\title{
TRAÇANDO AS IMAGENS DO TEMPO \\ ATRAVÉS DA EDUCAÇÃO, DA TECNOLOGIA E DO TRABALHO
}

\author{
Gyselle Antunes ${ }^{1}$ \\ Maria Cristina França ${ }^{2}$ \\ Sheyla Santos ${ }^{3}$
}

\section{Introdução}

O Instituto Federal de Educação, Ciências e Tecnologia do Rio Grande do Sul campus Porto Alegre surgiu de uma proposta política de incremento à educação brasileira através da Lei ${ }^{\circ} 11892$ de 29 de dezembro de 2008, juntamente com outras instituições federais de educação técnica profissional no país, totalizando 37 Institutos Federais (IFs) no Brasil.

A história da educação profissional em âmbito federal iniciou em 1909, quando então o presidente da República Nilo Peçanha, criou 19 escolas de Aprendizes e Artífices, dentre elas a Escola de Comércio de Porto Alegre, fundada em 26 de novembro de 1909 anexa a Faculdade Livre de Direito de Porto Alegre e seguindo sua trajetória vinculada à Universidade Federal do Rio Grande do Sul - UFRGS.

A partir desse momento, ainda sob a tutela da UFRGS, a então Escola Técnica de Comércio da UFRGS, após a consulta ampla à comunidade diretamente envolvida, passa por um momento de ruptura de vínculos que duraram mais de um século e, como Instituto Federal de Educação, Ciência e Tecnologia do Rio Grande do Sul, parte para a adoção de novos desafios.

Essa trajetória é narrada por interlocutores que fizeram e ainda fazem parte da Instituição e documentos com os relatos de dois antigos diretores acervados por conta da comemoração dos cem anos da Escola Técnica da UFRGS. Conforme Saturnino (2005), as memórias individuais servem como elementos de sustentação da memória coletiva, tecendo uma verdadeira rede, na qual, essas memórias individuais se entrelaçam, constituindo a memória social.

\footnotetext{
${ }^{1}$ Instituto Federal de Educação, Ciências e Tecnologia do Rio Grande do Sul - Campus Porto Alegre, Brasil.

${ }^{2}$ Instituto Federal de Educação, Ciências e Tecnologia do Rio Grande do Sul - Campus Porto Alegre, Brasil.

${ }^{3}$ Instituto Federal de Educação, Ciências e Tecnologia do Rio Grande do Sul - Campus Porto Alegre, Brasil.
} 
As informações foram obtidas por entrevistas semiestruturadas cujas narrativas orais atêm-se à trajetória institucional através da memória; e, com a mesma intensidade, adere-se ao uso de imagens fotográficas e videográficas que marcaram as passagens em diferentes épocas, como instrumento eficaz à qualificação das narrativas orais.

As imagens documentais através de seu caráter evocativo à memória dos entrevistados, servem como um elemento portador, comunicador e reforçador de identidades grupais, além de possibilitar a difusão de conteúdo maior que o documento escrito (Quintana, 2009).

Com base nisso, se visa à apropriação intelectual, por parte da sociedade, desse importante acervo histórico vivenciado por várias gerações como fontes perenes do saber, que atravessam tempos e lugares e se perpetuam em uma longa duração (Zonabend, 1980). Sendo a memória um elemento que constitui o sentimento de identidade de um indivíduo ou coletividade, ao mesmo tempo, age como base para um sentimento de continuidade, coerência e reconstrução (Pollak, 1992). A memória individual, portanto, existe sempre a partir de uma memória coletiva, visto que essa é tecida no interior de um grupo (Carvalhal, 2006).

Nessa direção, compreende-se que os últimos acontecimentos ocorridos com a instituição - formação dos Institutos Federais (IFs) e implicações dessa mudança - e com o campus Porto Alegre mais especificamente, desarmonizam o conjunto de referências que situa os sujeitos ao meio em que atuam, exigindo uma readaptação às realidades concretas dessa nova configuração. Conforme Candau (2011) "se a memória é 'geradora' de identidade, no sentido que participa de sua construção, essa identidade, por outro lado, molda predisposições que vão levar o indivíduo a incorporar aspectos particulares do passado, a fazer escolhas memoriais".

\section{Metodologia}

A presente pesquisa foi realizada através de estudo de caso com abordagem qualitativa, tendo como sujeitos fontes orais de grande relevância na trajetória e memória da instituição. Para isso foi usado como recursos metodológicos entrevistas semiestruturadas com a seleção de profissionais que atuaram em diferentes períodos na presente instituição, revisão bibliográfica, busca e organização de acervos imagéticos, documentos institucionais e periódicos. 
O estudo de caso, considerado como um dos formatos empíricos de investigação qualitativa consiste na observação detalhada de um contexto ou indivíduo, utilizando como fonte documentos ou acontecimentos específicos (Bogdan e Biklen, 1994).

Assim, a metodologia empregada no estudo de caso prevê o acesso, entendimento e interatividade da história do IFRS campus Porto Alegre, da sua memória e trajetória, através do emprego da mídia impressa e digital e de ambientes virtuais híbridos e foi realizado com o auxílio de duas câmeras, um tripé e dois gravadores de voz, utilizando plano americano na captação das imagens das entrevistas e suas narrativas e imagens foram submetidas ao consentimento informado (ou livre e esclarecido) dos entrevistados.

Nesse ínterim, o teórico Daniel-Henri Pageaux, salienta que imagem é entendida como representação de uma realidade cultural por meio da qual, aqueles que a elaboram, revelam e traduzem seu próprio espaço cultural e ideológico. Já Paul Ricoeur defende que a ideologia possui uma função integradora, sendo uma interpretação idealizada por meio da qual um grupo se representa, reforçando assim, sua identidade. Outro teórico da sociologia visual, Pierre Bourdieu, afirma que a fotografia pode ser tomada como documento de sociabilidade, expressando a diversidade de mentalidades e perspectivas, como material de referência (Camargo, 1992; Martins, 2002).

\section{O contexto histórico de Porto Alegre no início do século XX}

A Belle Époque (Bela Época) foi assim denominada, também, pelas suas inovações tecnológicas nos meios de transporte, no conhecimento médico e científico, entre outras, que marcaram o final do século XIX e início do século XX. Como em outras situações, esse foi um modelo europeu importado e acolhido em Porto Alegre no começo do século, fase de importante transição do regime monárquico para a república, sendo bem representado na Grande Exposição do Rio Grande do Sul, nos Campos da Redenção, hoje, Parque Farroupilha, que colocou o estado em evidência nacional e mundial, com seus 2.200 expositores, demonstrando as riquezas naturais, indústria, artes e ciências (Axt e Scliar, 2011; Pesavento, 2004).

A Redenção se engalanou para apresentar uma das mais notáveis Exposições que a cidade viu em todos os tempos. Essa Exposição foi uma espécie de apoteose do Século XX! (Sanhudo, 1961 apud Axt e Scliar, 2011) 
Durante esse período de grande expansão, a cidade que, contava já com uma população de 73.274 habitantes em 1900, teve na política rio-grandense, a influência do positivismo de Auguste Comte, com ideais de progresso, uma remodelação urbana, tanto coletiva quanto individual, que permearam essa época e ocasionaram profundas transformações na sociedade, sendo a iniciativa privada estimulada em todas as áreas, incluindo o ensino (Pesavento, 2004).

Essa modernização da cidade, juntamente com o advento da imigração estrangeira, pressupõe uma preocupação quantitativa da escola, tanto para combater o analfabetismo, para aumentar o número de eleitores, quanto qualificar a mão de obra desse novo trabalhador urbano, sendo que, nessa época, já começava a se notar um certo predomínio do setor urbano sobre o rural (Cardozo, 1986). Podemos pensar esse período como mais um ciclo desenvolvimentista e, como medida estratégica, o ensino profissionalizante passa a ser valorizado e ampliado.

Então, em 1900, foi inaugurado o prédio da Escola de Engenharia, com projeto arquitetônico influenciado pelo estilo positivista do engenheiro João Pereira Parobé e considerado decisivo para o governo escolher este como o local para a Grande Exposição de 1901. Depois do sucesso deste evento, foram cedidos terrenos para a construção do Ginásio Júlio de Castilhos, onde hoje se localiza a Faculdade de Economia, além dos prédios do atual campus da Universidade Federal do Rio Grande do Sul.

A partir de então, a cidade se desenvolveu e junto com a eletricidade, veio os trilhos dos bondes, os primeiros automóveis, ferrovias que diminuíam as distâncias e facilitava o comércio, sistema de abastecimento de água e esgoto e, em 1909, já funcionava regularmente três salas de cinema em Porto Alegre. Nessa mesma fase, a cidade também passou a demonstrar o outro lado do desenvolvimento, como a falta de saneamento básico, as precárias condições de trabalho nas fábricas e, portanto, a luta de classes (Axt e Scliar, 2011).

Milhares de trabalhadores nacionais, imigrantes ou recém-emancipados da escravidão, ofereciam força de trabalho às novas empresas que emergiam, principalmente, indústrias alimentícias e têxteis. Nesse cenário efervescente, a condição portuária da cidade favoreceu a proliferação e circulação de tendências ideológicas do movimento operário na Europa, como o socialismo e o anarquismo.

Tais ideias se transformaram nos princípios orientadores do movimento operário gaúcho, onde, entre outros, lutavam pelos princípios de ampla liberdade de imprensa, 
direito de voto à mulher, redução da jornada de trabalho para 8 horas, instrução geral e profissional gratuita, etc (Petersen e Schmidt, 2004).

Dois dos eixos norteadores da pesquisa, a educação e o mundo do trabalho, constituem a trajetória da Instituição com narrativas bibliográficas e, por meio delas, o resgate das memórias dos sujeitos que fizeram e fazem parte do IFRS campus Porto Alegre e das histórias que contemplaram a formação da identidade institucional. Apesar das alterações que passa ao longo da sua história, o atual IFRS - campus Porto Alegre mantém a missão de qualificar profissionais para o mercado de trabalho, perpetuar com a realização de pesquisa e desenvolvimento de processos, produtos e serviços em colaboração com o setor produtivo.

Segundo Herrlein Jr (2000), neste contexto histórico da virada de século, a oferta restrita de força de trabalho para a crescente indústria na cidade, contribuiu para os níveis regionais de salários médios mais elevados, se comparada com o restante do país. Ademais, a maior parte da população urbana pobre e da classe média provinha ou do campo ou eram ex-escravos, sem escolaridade (Amaral, 2001). Dessa forma, além de benfeitorias urbanas, o mercado passou a demandar mão de obra qualificada.

Buscou-se, então, reordenar o tecido social e cultural, no qual os fios da história do Instituto Federal do Rio Grande do Sul, campus Porto Alegre, se entrelaçam.

\section{Tecendo o tempo}

Em 1979 o Professor Paulo Gilberto Fagundes Vizentini publica uma obra em comemoração aos setenta anos da Escola Técnica de Comércio "Do Curso Geral à Escola Técnica de Comércio (1909-1979) - A história do ensino comercial de segundo grau na UFRGS”. O autor narra que no inicio do século XX no Rio Grande do Sul estava sob uma ascensão comercial e industrial e devido à inexistência de cursos de formação universitária e técnica havia uma carência na mão-de-obra nesses setores. Segundo Vizentini, para entender o que acontecia no início do século XX era preciso buscar os acontecimentos sociais, ou seja, a influência do positivismo no Estado, o qual apregoava a necessidade de se incrementar o ensino técnico para satisfazer a rápida demanda no mercado de trabalho, como condição para o desenvolvimento (Vizentini, 1979: 9).

Desse modo, sob a influência do positivismo criou-se um Projeto da Escola de Comércio pelos professores Manoel André da Rocha, Dr. Leonardo Macedônia Franco 
e Dr. Francisco Rodolpho Simch, feito o projeto, o mesmo foi estudado por uma Comissão Especial que compunha os professores Desembargador Valentim do Monte, Ministro Plínio Casado e Dr. Normélio Rosa. E, aos vinte e seis dias do mês de novembro do ano de 1909 foi fundada a Escola de Comércio, anexa à Faculdade Livre de Direito.

Figura 1 - Prédio da Faculdade Livre de Direito.

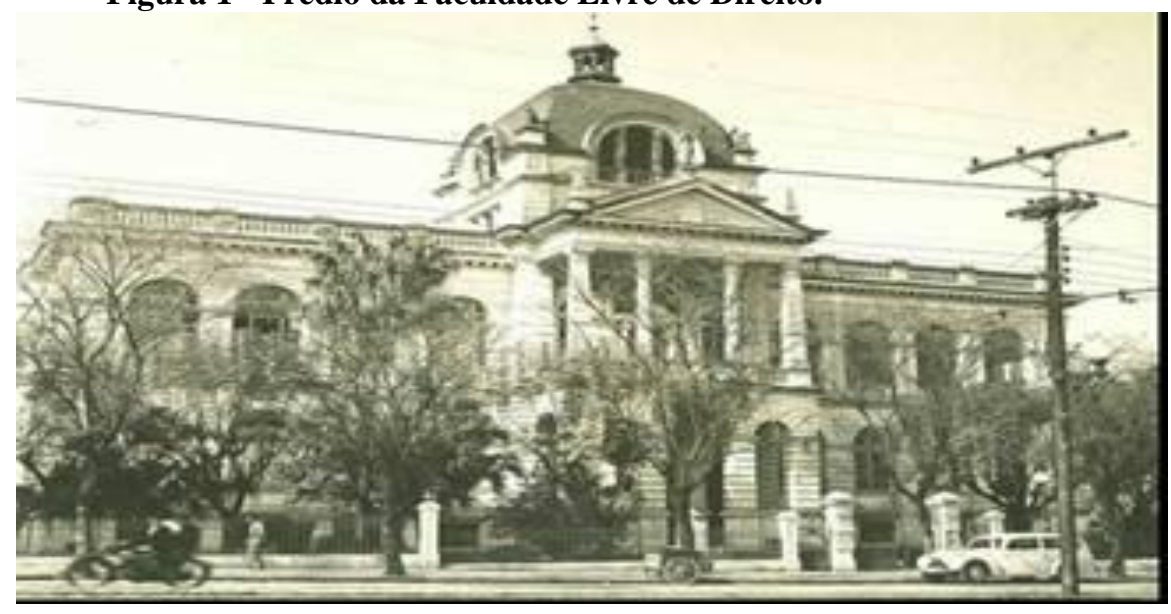

Fonte: Acervo Museu UFRGS

A primeira turma constituída por treze alunos formou-se no Curso Geral em 1911, cujo curso habilitava aos cargos da Fazenda com a função de guarda-livros e perito judicial não necessitando de concurso público para assumir o cargo na Fazenda. Desses, oito alunos concluíram o Curso Superior como Bacharéis em Ciência Comercial no ano de 1913 e habilitava o acesso aos cargos, sem concurso, no Ministério das Relações Exteriores, Corpo Consular, Atuário de Companhia e chefes de Contabilidade de Empresas Bancárias e Grandes Casas Comerciais. Em 1916 através de um Decreto no 3169, de 04 de outubro, declarava a Escola de Comércio de Porto Alegre uma instituição pública: "Essa declaração de utilidade pública vem-nos demonstrar a preocupação que o governo tinha com esse tipo de ensino, mal transcorrido seis anos de funcionamento da escola" (Vizentini, 1979: 11).

A estrutura inicial da escola foi preservada até 1931, com poucas alterações. Com a Revolução de 1930 surgiu o Decreto no 20.158 que estabelecia uma nova organização para os cursos comerciais no Brasil, e a Escola ajustou-se a essas novas normas educacionais. Essas mudanças tiveram grandes dificuldades em adaptar-se ao novo sistema (durante dois anos não se formou nenhum aluno). Devido a esta adaptação, a Faculdade de Direito aceitou a sugestão para a criação de um Curso Propedêutico, com 
duração de três anos, assim solucionando o problema da adaptação e em 13 de maio de 1933, coloca a Escola na órbita da Legislação Federal e inicia uma nova fase de grandes realizações.

Desde sua fundação a Escola de Comércio de Porto Alegre foi dirigida pelo Professor Desembargador Manoel André da Rocha até o ano de 1935, e tendo como local de funcionamento o subsolo da Faculdade Livre de Direito. A Universidade de Porto Alegre foi criada em 1934 e a Faculdade Livre de Direito e a Escola de Comércio foram integradas a ela. Para tornar possível essa criação da Universidade, segundo (Vizentini, 1979: 13) "O General Flores da Cunha, interventor federal, nomeou uma comissão composta pelos senhores João Carlos Machado, Leonardo Rodolpho Simch, Martin Gomes, Guerra Blessmann, Egidio Hervê e Ary de Abreu Lima". Com a integração á Universidade de Porto Alegre, a Escola de Comércio e a Faculdade Livre de Direito passaram a ser custeada pelo Estado.

Com a formação da Universidade o então Diretor da Escola de Comércio, o Desembargador Manoel André da Rocha foi nomeado como Reitor da Universidade de Porto Alegre, deixando assim o seu cargo como diretor ao professor Luiz Mello Guimarães que ficou no cargo de 1935 até 1938, passando a direção da Escola de Comércio ao professor Leonardo Macedônia Franco e Souza, posteriormente ao professor Edgar Luis Schneider no ano de 1940 e por fim ao professor Edgar Ferreira Paes que permaneceu na direção da instituição de 1942 a 1945.

A Escola de Comércio conheceu um período de estabilidade entre os anos de 1934 e 1945 com realizações que elevaram os conceitos junto à comunidade e ao curriculum do Curso Técnico de Perito-Contador que era divulgado por ser bastante completo e com nível satisfatório. Neste período houve um aumento dos candidatos em número e nível dos alunos para a Escola de Comércio à procura do Curso Técnico de Perito Contador, como também um aumento dos candidatos a alunos da Universidade de Porto Alegre.

A Faculdade de Economia e Administração, durante o mandato do professor Atílio Machado da Rosa (1949-1952), passou a ser federalizada dando inicio a uma nova fase na história da Escola Técnica de Comércio que foi integrada à Universidade do Rio Grande do Sul, sendo então mantida pelo governo federal através da Lei $\mathrm{n}^{\circ} 1.254$ de 4 de dezembro de 1950. Essa nova fase trouxe a criação de novos cursos, sendo um deles o Curso Técnico de Administração, em 1954, o Curso Técnico de Secretariado, em 1958, e os cursos de Educação à distância. Para esses cursos técnicos, realizou-se 
um convênio com o Departamento do Serviço Público do Governo do Estado para os servidores públicos, que se destinava ao ensino de nível médio para administração pública, administração de pessoas, organização e serviços, psicotécnica e técnica orçamentária. A coordenação desses cursos esteve ao cargo do professor Francisco Rodrigues de Carvalho. No ano de 1957 a escola passou a promover o curso de Educação à distância para os servidores públicos que moravam no interior do Estado por correspondência. Conforme Paulo Vizentini dentro da instituição havia a "Campanha de Aperfeiçoamento no Ensino Comercial".

Ao ser colocado em prática essa campanha promoveu cursos de aperfeiçoamento em diversas disciplinas relacionadas ao Comércio em várias cidades do interior: administração de empresas, organização e contabilidade comercial, organização e contabilidade industrial, legislação tributária fiscal, entre outros. Formaram-se no Curso de Formação e Aperfeiçoamento de Professores do Ensino Comercial 480 alunos entre os anos de 1956 e 1971.

No período dos anos 1970 a 1979 a Escola Técnica de Comércio ganhou autonomia em relação à Faculdade de Ciências Econômicas, passando a ter uma adoção orçamentária própria. Em 1975 abriu vagas para o Curso Técnico em Operador de Computador e em 1976 para o Curso de Transações Imobiliárias, um curso pioneiro no país. Ainda neste período a Escola Técnica de Comércio passou a ministrar as aulas em dois turnos, o Curso Técnico de Secretariado começou a funcionar também no turno da noite.

Nos anos seguintes, as décadas de 1980 e 1990 foram marcadas pela participação da comunidade escolar, tendo o professor Aldo Antonello Rosito como o primeiro diretor eleito da Escola Técnica de Comércio.

O professor Paulo Schinini conta com carinho a época em que permaneceu atuando como professor na Escola Técnica de Comércio da UFRGS, iniciando suas atividades de docência na década de 1980. Muito simpático e carismático o professor Paulo Schinini foi convidado a lecionar e assim repassou seus conhecimentos e ensinamentos a centenas de jovens e adultos atuando na escola por mais de uma década. Em sua narrativa, Schinini relembrou toda sua trajetória como professor de ensino técnico iniciando sua carreira de docência como professor na Escola Técnica Agrícola (ETA) na cidade de Viamão. Percorreu diversas cidades do interior do Rio Grande do Sul, sendo sempre reconhecido pelo seu maravilhoso trabalho. Concluiu o curso de 
Direito como sua segunda graduação de nível superior, atuando assim na interdisciplinaridade dos cursos da área comercial da Escola.

[...] aqui eu lecionava, daquele prédio do lado, o curso de segundo grau. Escola técnica federal, eu dava aulas de escrituras no campo de Direito, na área comercial [...] Os alunos são encantados, eles me deram uma matéria que no final era fazer contratos, tudo isso era comigo. (Professor Paulo Schinini, 87 anos).

$* * *$

Figura 2 - Sala de aula da Escola Téenica de Comércio, anos 1980.

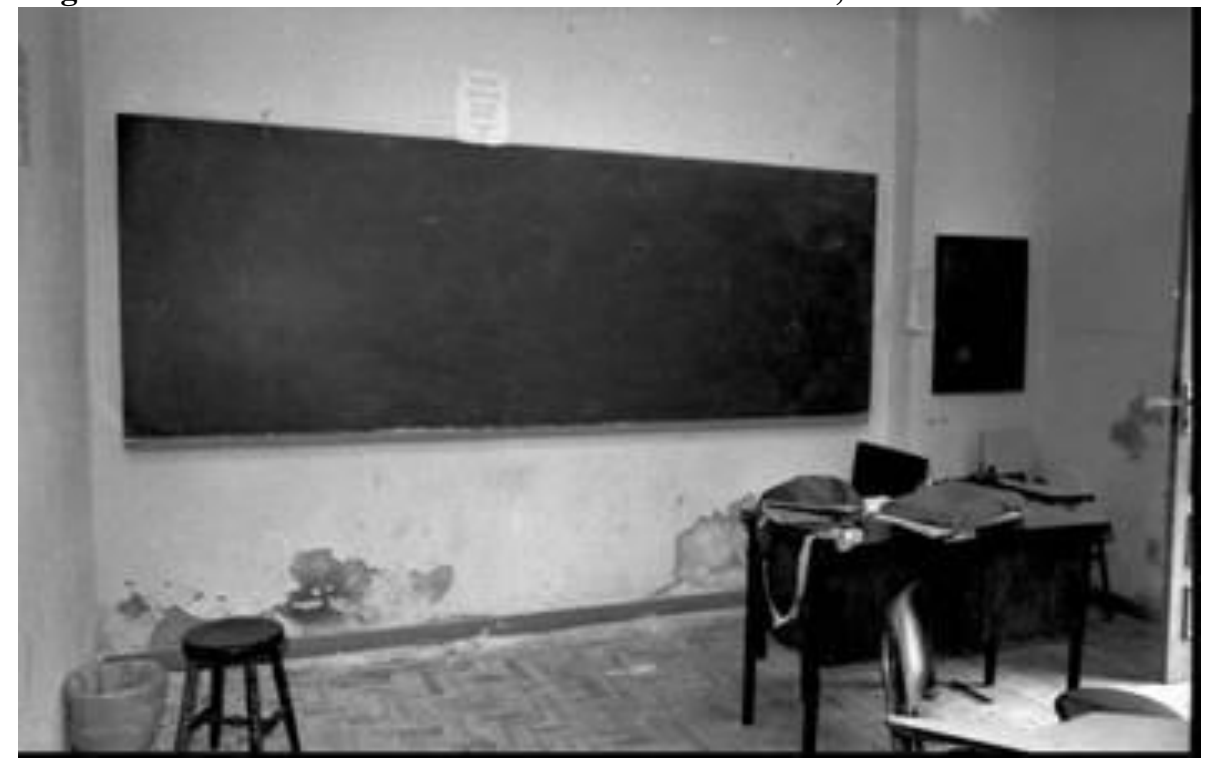

Fonte: Museu da UFRGS

Nessa mesma década, em agosto de 1982, como um projeto de extensão universitária no ensino da música, na Universidade Federal do Rio Grande do Sul (UFRGS), formou-se o embrião do que hoje é o "prelúdio", projeto que continuou sua jornada, agora, com seu lugar próprio, junto ao IFRS campus Porto Alegre. Resultado de um trabalho participativo da coordenação, professores e alunos, constituindo uma proposta pedagógico-musical bem-sucedida, com seus 30 anos completos de existência e seguindo os objetivos fundamentais desde a sua origem, quais sejam, a inclusão, a acessibilidade e a construção do conhecimento, além do desenvolvimento do potencial criativo de seus alunos (Kiefer, 2005).

No ano de 1985 o professor Aldo Antonello Rosito assume as funções de diretor da escola, substituindo dois grandes antecessores e eméritos educadores, os professores Clóvis Vergara Marques e Aldriovando Rodrigues. Procurou manter a mesma filosofia preconizada por seus antecessores: a busca de um ensino técnico com qualidade, sem 
descuidar da formação do aluno como individuo na sociedade. Procurou, também, a busca de recursos junto a órgãos financiadores externos para modernizar os laboratórios, biblioteca, equipamentos de informática e a parte administrativa da Escola.

Assim, montou os laboratórios de Informática, de Química, de Mecanografia e, na mesma época, ocorreu um aumento do acervo da Biblioteca, a modernização do setor de informática e da secretaria da Escola. Igualmente, neste período, ocorreram diversos seminários pedagógicos com professores para atualização das grades curriculares dos diversos cursos técnicos mantidos pela Instituição. E, em 1988, foi efetuada a primeira eleição para a Direção para a Escola, após 79 anos de existência. Nessa ocasião, o professor Rosito foi eleito como o primeiro diretor da escola juntamente com a vicediretora professora Liana Yara Richter. Conforme o professor Aldo Antonello Rosito:

Tínhamos diversos desafios e projetos, como por exemplo, a construção de um novo prédio, já que a Escola estava naquele local, na Avenida João Pessoa, nos fundos da Faculdade de Ciências Econômicas desde 1953, e crescendo em numero de alunos. Tínhamos o projeto de busca de recursos extra-orçamentários para aquisição e manutenção de equipamentos modernos para os laboratórios e para aperfeiçoamento dos docentes e dos técnicos administrativos. (Rosito, 2009: 2)

O professor Walter Karwastzik iniciou suas atividades como professor substituto na área da Geografia nos finais dos anos 1980. Realizou um concurso público após o termino do contrato como professor substituto, permanecendo até os dias atuais no IFRS- campus Porto Alegre. Em sua narrativa, professor Walter conta a trajetória da Instituição traçando as imagens do tempo e compondo a identidade institucional. Momentos estes, que foram marcante às adoções a novos projetos, como a passagem dos prédios onde localizava a Escola. Passando do prédio anexo a Faculdade de Economia na Rua João Pessoa para a Rua Ramiro Barcelos.

[...] funcionava ali na João Pessoa, $n^{\circ}$. 52, anexo fundos. Era um endereço que não era nem um pouco nobre, né? Mas, assim, me assustei um pouco, quando cheguei assim, porque era uma escola desmembrada, uma escola que não tinha um corpo, né, era dividida, as salas ficavam um pouco pra lá um pouco pra cá, ocupando dependências da Faculdade de Economia, da Faculdade de Direito, uma hora era um pátio comum a todos, tinha hora que você não sabia se eram alunos da escola ou eram alunos das faculdades que existiam por ali (Walter Karwastzki , 53 anos).

Um grande passo foi a construção de um prédio próprio para a Escola Técnica de Comércio, iniciado em abril de 1987. A partir desse momento foram efetuadas várias reuniões, levantamento de dados relativos a problemas de expansão da escola e estudos 
de localização do prédio. Em setembro de 1989 foi concluído o projeto, com uma área de cerca de $4.000 \mathrm{~m}^{2}$ e levado ao Gabinete do Ministério da Educação.

Nessa mesma época a Universidade destinou o terreno localizado à Rua Ramiro Barcelos para que ali fosse erguida a nova Escola. No dia 26 de novembro de 1989 data em que a escola comemorou seus 80 anos de existência, foi lançada a pedra fundamental da construção.

\begin{abstract}
Os recursos financeiros para o inicio da construção foram conseguidos pelo Professor Aldo Antonello Rosito, diretor da Escola Técnica, entre 1988 e 1992 o qual teve a oportunidade de, junto comigo, colocar a pedra filosofal num terreno que estava destinado a uma unidade nobre da Universidade, que ainda não estava definida. E, devido á conclusão de um curso de atualização da língua portuguesa para jornalistas na sede do Planetário, onde a imprensa de Porto Alegre estava toda reunida e o curso era promovido pela Associação Rio-grandense de Imprensa e oferecido pela Escola Técnica, houve a oportunidade de realizar uma solenidade um tanto quanto de surpresa para a administração da Universidade de colocação da pedra fundamental nesse espaço físico, cujo ato apareceu nos mais diversos jornais da cidade na edição do dia seguinte, o que garantiu, definitivamente que aquele terreno seria o da construção da nova Escola Técnica (Richter , 2009: 3).
\end{abstract}

Foi uma mudança em termos de infraestrutura de 0 para 100. Nós passamos a ter salas mais confortáveis, mais laboratórios, quando a gente mudou para o prédio, em seguida surgiram novos cursos, química e biotecnologia, acho que segurança do trabalho, se não me engano (Prof ${ }^{\mathrm{a}}$. Laura Vellinho).

No ano em que completava 80 anos de instituição a Escola Técnica de Comércio da UFRGS colocou a disposição da comunidade porto-alegrense o curso Técnico em Segurança do Trabalho, abrindo grandes possibilidades de trabalho nesta área carente e crescente no sul do país. Em 1994 foi inaugurado o prédio da Escola Técnica (Figura 2) na Rua Ramiro Barcelos, no 2777, bairro Santana, na capital (Figura 3). Uma publicação da Escola Revista, periódico da Escola Técnica de Comércio (ETC), cita uma entrevista da diretora Liana Richter sobre a importância da obra construída, observando a área de $4.800 \mathrm{~m}$ das novas instalações permitindo assim um número maior de alunos. Este foi um grande marco na trajetória da Instituição. As instalações da Escola Técnica de Comércio estavam precárias e com a construção do novo prédio "da Ramiro" eram ofertadas novas perspectivas para o futuro da escola. 


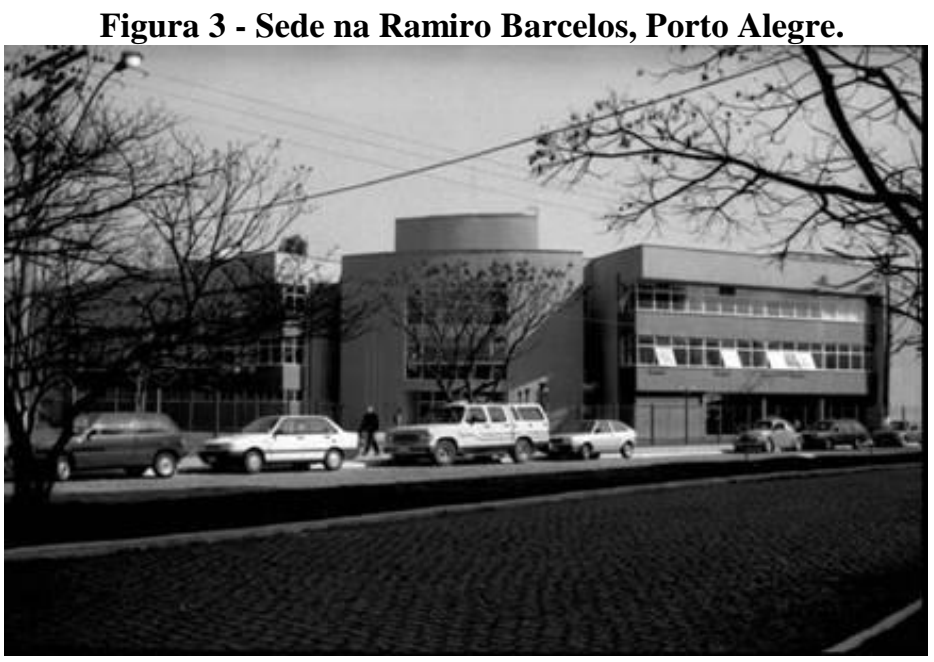

Fonte: Acervo Museu UFRGS

Figura 4 - Deslocamento da Escola Técnica do antigo endereço, no campus central da UFRGS, para a sede própria, na Avenida Ramiro Barcelos.

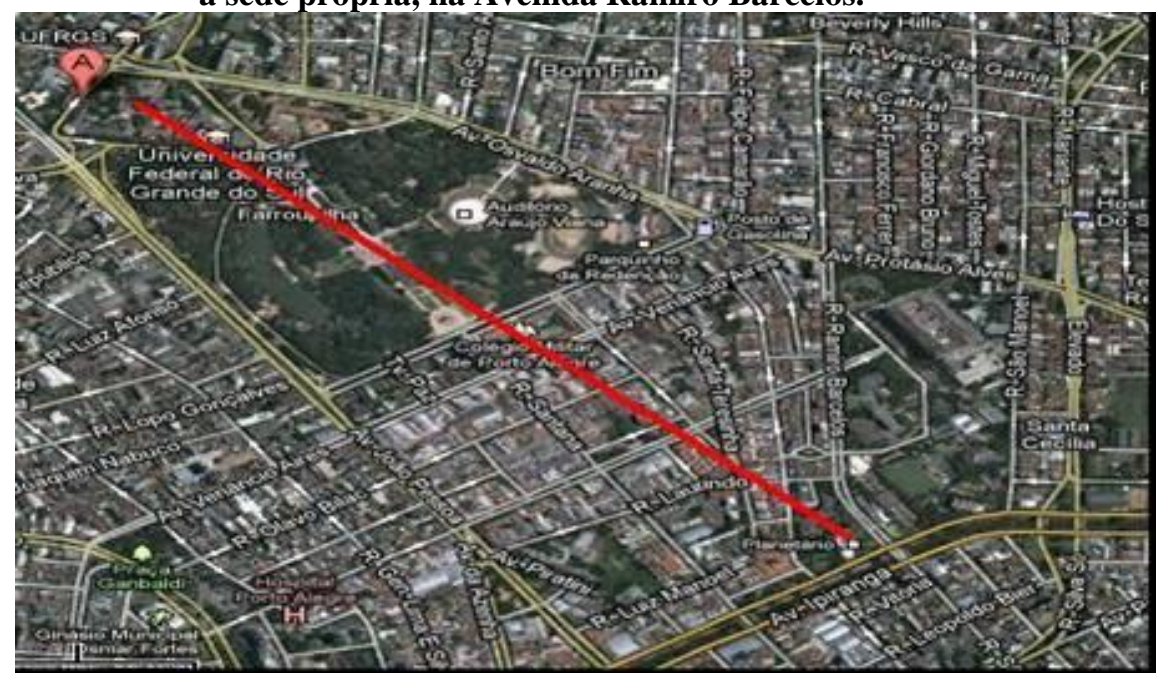

Fonte: Google Maps

Neste período também houve a criação de sete cursos novos, alguns inovadores à sua época: Suplementação em Processamento de Dados, Técnico em Química, Técnico em Biotecnologia, Pós-Técnico em Controle Ambiental, Pós-Técnico em Redes de Computadores, Suplementação em Secretariado, Técnico em Biblioteconomia. Ocorreu a criação do Núcleo para Portadores de Necessidades Especiais (NAPNE), com inúmeros cursos e atividades, respeitando os Direitos Humanos. De fato, com algumas alterações nas nomenclaturas, os cursos permanecem até os dias atuais. 


\title{
O novo ciclo: da Escola Técnica para Instituto Federal do RS - Campus Porto Alegre
}

O IFRS - Campus Porto Alegre surge através de uma proposta de política de educação brasileira a Lei Federal no 11892108 , onde se criou 38 Institutos Federais de Educação, Ciência e Tecnologia (IFs), distribuídos por todo o país, com o intuito de desenvolver um novo modelo de Educação Profissional e Tecnológica. Atualmente, em nosso estado, o campi é formado por 12 IFs, nas cidades de Bento Gonçalves, Canoas, Caxias do Sul, Erechim, Farroupilha, Feliz, Ibirubá, Osório, Porto Alegre, Restinga (Porto Alegre), Rio Grande e Sertão.

A conversa sobre a migração da escola técnica para o Instituto Federal surgiu antes da aprovação da Lei Federal, com o Projeto de Lei em andamento, existia a possibilidade de aderir a novos projetos com a adoção. Fez-se todo um processo de consulta com a comunidade onde acabou aceitando a proposta de mudança. As duas chapas que concorreram à eleição trabalharam com essa perspectiva de mudança. A eleição ocorreu no dia 03 de outubro de 2008.

\begin{abstract}
Esse processo de desmembramento da UFRGS e transformação da Escola em uma unidade do Instituto Federal foi importante para a escola, ela cresceu. Claro que houve problemas políticos, a Reitoria era para ser em Porto Alegre, a Lei que foi para o Congresso determinou Porto Alegre como uma das reitorias do IFRS, mas por um ato político o governo, na hora lá, um deputado federal da região da serra, riscou o nome "Porto Alegre" e botou "Bento Gonçalves", e foi, assim, aprovado. Portanto, o Rio Grande do Sul passou a ser o único estado que não tem uma reitoria na capital (Prof. Lúcio Olímpio de Carvalho Vieira).
\end{abstract}

O professor Paulo Roberto Sangoi, que lecionava no curso Técnico de Transações Imobiliárias se candidatou à vaga e precisava de um candidato a vice-diretor. Foi então que o professor Marcelo Schimit, diretor na época, sugeriu um professor do curso de Biotecnologia, o professor Julio Xandro Henck para concorrer à direção como vicediretor em sua chapa.

\begin{abstract}
São os encontros da vida, eu achava que tinha um ano e meio, era recente, coordenador da biotecnologia e a gente passou por uma eleição, a gente ganhou a eleição e ficamos treze, quatorze dias como diretores da escola técnica e porque logo na seqüência houve a migração para o Instituto (Prof. Julio Xandro Heck, 35 anos).
\end{abstract}

O ano de 2009 foi crucial para a consolidação como IFRS, foi o ano em que tudo havia de ser feito. Ao deixar de ser Escola Técnica de Comércio, uma das medidas significativas foi a de transformá-la também em uma instituição de ensino superior, além 
do ensino técnico. Porém, essa transformação exigiu medidas de grandes dimensões, tais como: o concurso público, a negociação com a UFRGS, a construção de normas, etc. Mesmo com a quantidade de entraves, o que levou a Escola Técnica de Comércio, através de decisão dos servidores da época, partir para a adoção a novos desafios foi a proposta a partir da Lei Federal 11.892/2008 com a perspectivas de melhorias para a educação, oferta e serviços oferecidos à comunidade porto-alegrense. Segundo o professor Paulo Sangoi, atual diretor do Campus Porto Alegre:

Ser o diretor, ser o reitor que perde uma escola centenária, que é mais antiga que a própria universidade, isso foi analisado por muito tempo. Dentro do conselho universitário (CONSUP) foi feito todo um trabalho, um lobby de convencimento por parte dos professores da Escola Técnica (Diretor Paulo Roberto Sangoi, 49 anos).

Em 2011, o campus Porto Alegre dá um salto significativo em direção à expansão, com a inauguração de sua nova sede própria, localizada no Centro Histórico, na Rua Cel. Vicente, 281, com uma estrutura capaz de ampliar a oferta de vagas e novos cursos à comunidade porto-alegrense (Figura 4).

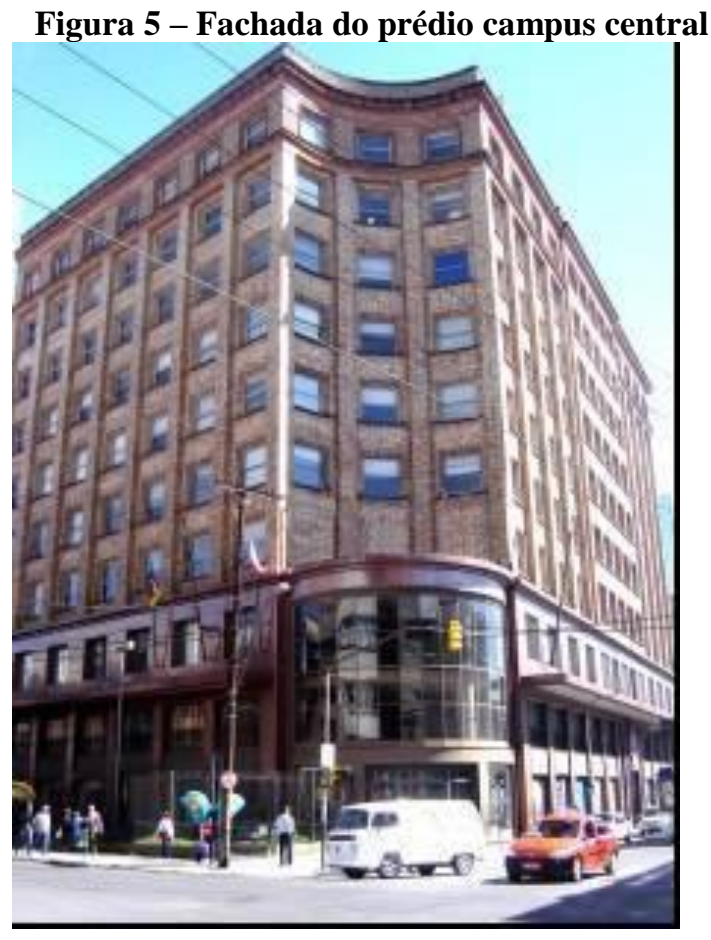

Fonte: Institucional 


\section{A trajetória dos alunos}

As imagens remetem à memória e a trajetória do IFRS - campus Porto Alegre mostrando as feições dos alunos e as características da educação profissionalizante por mais de um século de existência na cidade de Porto Alegre. Em sua Fundação no ano de 1909 os alunos da instituição eram adultos, homens, que buscavam para o aperfeiçoamento profissional para assumir cargos bancários e cargos públicos. Com o passar dos anos, a abertura de novos cursos e o aumento do número de vagas, a Escola de Comércio passou a ofertar os cursos técnicos para todos, e na década de 1950 as primeiras mulheres se matricularam para ingressarem no curso técnico de administração e contabilidade.

As imagens institucionais dos anos 1970 mostram a disponibilidade da oferta dos cursos técnicos para todos, sem distinção de cursos especificamente para homens e mulheres. Isso consequentemente remete ao perfil dos profissionais e a demanda do mercado de trabalho, pois em algumas profissões deixaram de ser exclusivamente para um determinado gênero, como por exemplo, o contador, o administrador. As mulheres começaram a buscar seu espaço no mundo do trabalho, e as imagens do tempo mostra esta mudança na sociedade porto-alegrense.

Nos arquivos impressos e digitais, como os relatórios dos estudos para traçar o perfil dos alunos mostram as mais variadas realidades socioeconômicas, pois encontrase desde os alunos com vulnerabilidade social, até os alunos que possuem especializações em cursos superiores e procuram a Instituição para aperfeiçoar e adquirir novos conhecimentos.

Desde a sua fundação, com o Curso Geral e o Curso Superior ainda anexo a Faculdade Livre de Direito de Porto Alegre e passando por todas as rupturas e adoções a novos projetos, a Instituição manteve-se preocupada em adequar o ensino oferecido para a sociedade de forma com que os cursos técnicos possibilitassem a possibilidade, de oferecer educação aos mais diferentes públicos: os que procuram uma formação profissional há aqueles que buscam aperfeiçoamento, os que desejam mudar de profissão e têm os que querem agregar mais de uma ocupação.

Como nos demonstrou o relato do Sr. Oswaldo Carlos Schwanke, corretor de seguros aposentado, aluno do curso de contabilidade da Escola Técnica, um curso muito disputado na época e que serviu de base para seu ingresso no curso de Economia na UFRGS: 
Eu vim para Porto Alegre e fiz o supletivo no colégio estadual Julio de Castilhos e inicie um período de estudos de onze anos, depois de completar o ginásio vim para Escola Técnica. E comecei a Escola Técnica em Contabilidade, esse curso eu completei na Escola Técnica. (Sr. Oswaldo C. Schwanke).

Figura 6 - Alunos da Escola de Comércio, 1970.

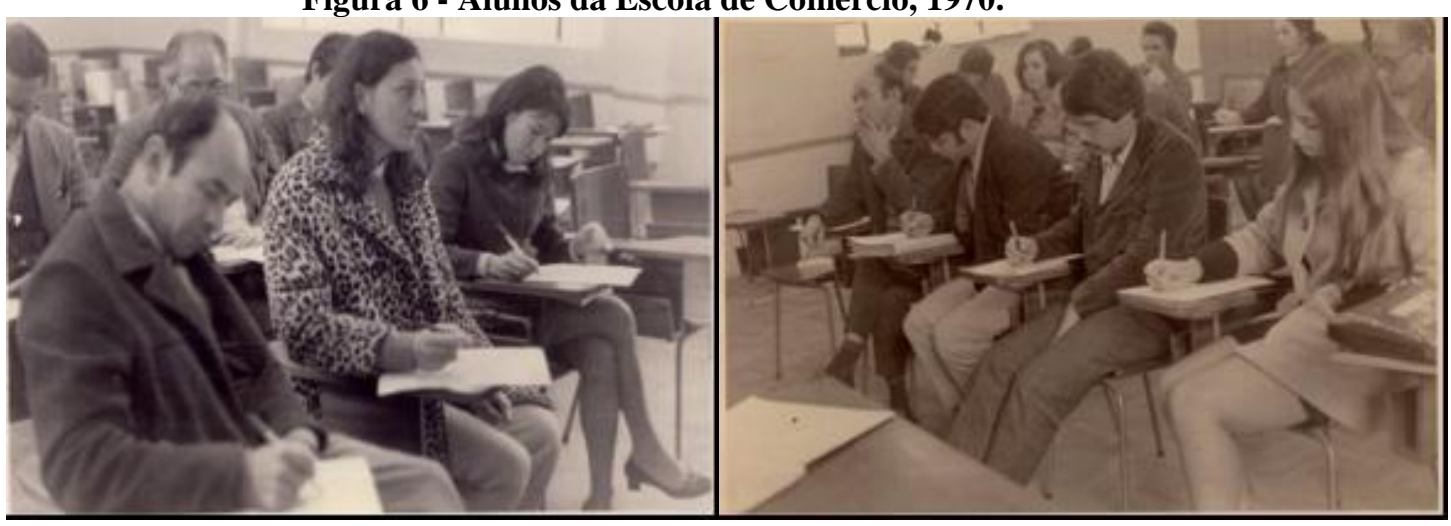

Fonte: Documentos institucionais

Hoje, o IFRS - Campus Porto Alegre possui cinco cursos superiores e dezessete cursos técnicos, presenciais e à distância. Oferece, ainda, o PROEJA, pós-graduação e cursos de extensão e capacitação profissional, alguns através de convênio com instituições parceiras, como o Grupo Hospitalar Conceição (GHC), totalizando o número de 1.582 alunos vinculados.

\section{Os primeiros rumos à tecnologia}

A trajetória e as memórias da tecnologia presente na Instituição é marcada com ênfase na narrativa da professora Laura Velhinho Corso. Ao ingressar na então Escola Técnica de Comércio, a tecnologia era condizente com a época, segundo a Professora, era tudo muito arcaico, não existia a tecnologia que têm-se atualmente. As salas de aulas eram precárias, não ocorria a disponibilidade de uma máquina copiadora ou um projetor de slides.

Os primeiros aparelhos demoraram a chegar na Escola, as aulas eram a moda antiga, com o professor, livros e giz para escrever no quadro. 
Quando eu ingressei tinha mimeografo, neste prédio aqui, logo que a gente entrava tinha uma salinha e quem reproduzia as copias era o Paulinho. O Paulinho era um funcionário, não sei se aposentou, mas ele não veio para o instituto, ele ficou na UFRGS e era um funcionário da FABICO, na portaria. Então o Paulinho que fazia as copias pra nós. [...] Depois veio o xerox, eu me lembro de que no inicio eu fazia matriz. E era matriz era xerox, aquele cheiro de álcool. Era um mimeografo para a escola toda. E depois veio a maquina de xerox que ficava ali onde a gente reproduzia as copias. Então ficava ali o mimeografo e a maquina de xérox (Prof. ${ }^{\text {a }}$ Laura Velhinho Corso, 50 anos).

Ao assumir a direção no ano de 2009 o diretor Paulo Roberto Sangoi juntamente com o vice-diretor Julio Xandro Heck analisaram o que deveria ser investido por conta desta transformação que a Instituição estava passando.

Segundo o professor Sangoi, esta análise isso implicaria conscientemente em crescimento do número de alunos tanto curso. Para chegamos a uma outra categoria de ensino, a qual não poderíamos fazer, que seria a graduação, a pós graduação.

Com a ruptura e a adoção ao novo projeto, na posição de Instituto Federal, cinco cursos superiores foram implementados, e com eles a aquisição de materiais tecnológicos para suprir as necessidades materiais para os cursos, como compras de computadores e instalações para laboratórios de informática, laboratórios de análises ambientais e no curso de panificação.

Figura 7 - Laboratórios do novo prédio.

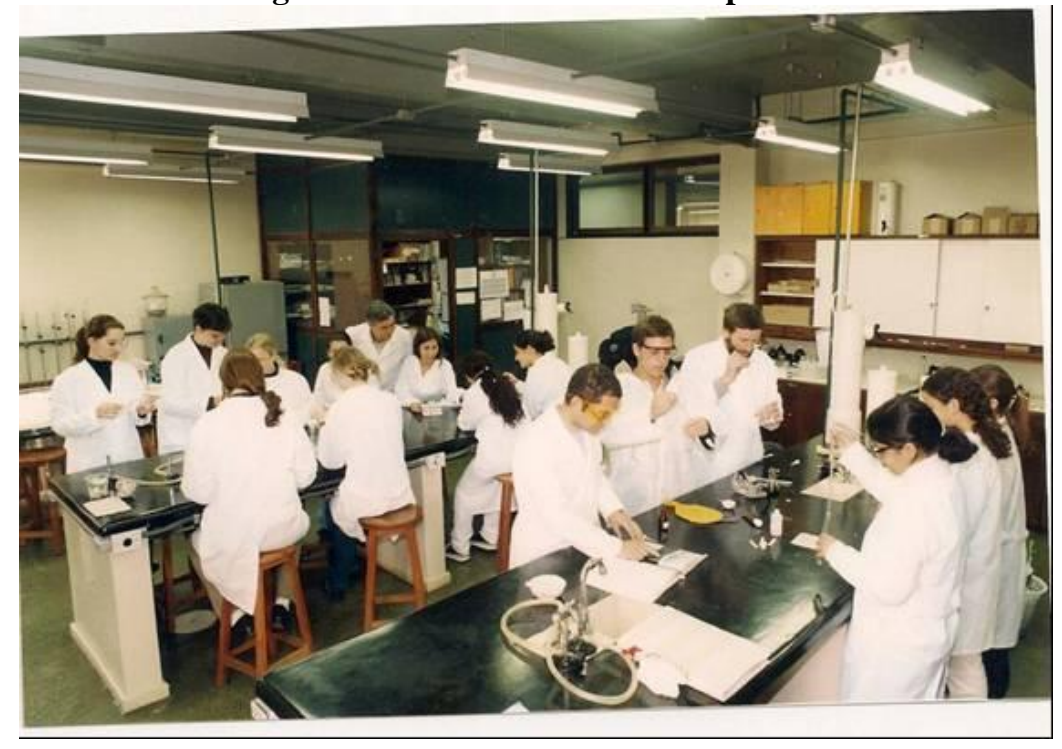

Fonte: Institucional

Outro grande avanço tecnológico foi à formação e aquisição de materiais para os gabinetes dos professores. Com o aumento no número de docentes com dedicação 
exclusiva, os gabinetes foram reestruturados com novos computadores, ar condicionado, etc. As salas de aula ganharam novos computadores e data-show.

\section{Considerações finais}

A pesquisa realizada até o presente momento mostra a série de alterações que resultaram no atual IFRS - Campus Porto Alegre. No que trata das alternativas de ensino pudemos observar que seu início, em 1909, houve rupturas e adoções a novos projetos, e a Escola Técnica sempre se preocupou a adaptar a essas mudanças qualificando seu ensino. Com a adoção a novos projetos, a Escola Técnica de Comercio passou a ofertar novos cursos dentre eles os cursos técnicos, consequentemente um maior numero de vagas dos cursos para a sociedade porto-alegrense. E em 2008 ocorre mais uma ruptura em sua trajetória que foi a desvinculação com a UFRGS e adoção a rede de Institutos Federais.

As narrativas que retratam os diferentes períodos que a instituição em questão foi submetida estão centradas nos acervos de imagens não só particulares como também institucionais distribuídos nos diferentes espaços que deram abrigo, no passado, a essa unidade de ensino e tecnologia. Desse modo, a memória dos atores que compuseram as trajetórias até aqui contempladas, tem nesses acervos o apoio às reminiscências, reconstruções e desdobramentos que o tempo encarregou-se de estabelecer.

A trajetória discorrida até aqui apresenta as alterações da vocação de ensino e tecnologia em concordância com diferentes tempos que, inscritos em um contexto mais amplo, tanto em nível regional, como nacional e, mais atualmente, em uma perspectiva global melhor observável, trazem como compromisso a formação de agentes sociais que atuem no mundo do trabalho de forma crítica e construtiva em direção a um mundo mais justo.

Considera-se, então, a mudança de espaço físico (saída da Rua Ramiro Barcellos para a Rua Voluntários da Pátria) um marco importante que contribui, em grande escala, na consolidação do IFRS - Campus Porto Alegre como uma nova instituição, não mais sob a tutela da UFRGS, mas como parceira no desenvolvimento da educação, da ciência e da tecnologia em âmbito local, estadual e nacional.

Ou seja, a ruptura dos vínculos institucionais representados na "mudança de moradia" implica em uma reflexão urgente sobre a identidade institucional e a reafirmação de uma prática educacional diferenciada que tem, na verticalização do 
ensino, a possibilidade de formação educacional densa, socialmente mais abrangente e de sistemática revisão sobre o que se pretende: um ensino público e de qualidade.

\section{Referências}

AMARAL, Sílvia Cristina Franco. Espaços e vivências públicas de lazer em Porto Alegre: da consolidação da ordem burguesa à busca da modernidade urbana. Revista Brasileira de Ciências do Esporte, Florianópolis, Santa Catarina, v. 23, n. 1, Jul. 2008. ISSN 2179-3255. Disponível em: <http://cbce.tempsite.ws/revista/index.php/RBCE/article/view/326/285>. Acesso em: 16 Mai. 2013.

AXT, Gunter; SCLIAR, Moacir. Parque Farroupilha "Redenção" Histórias de Porto Alegre, Paiol, 152p. 2011.

BOGDAN, Robert C.; BIKLEN, Sari Knopp. Investigação Qualitativa em Educação. Portugal, Porto: Porto Editora, 1994.

CAMARGO, Katia Aily Franco de - A imagologia e seus teóricos. In: Labirinto.Revista eletrônica do Centro de Imaginário.http://webcache.googleusercontent.com/search?q=cache:riI7r_ZLD8sJ:www.cei.unir .br/artigo92.html+imagologia\&cd=2\&hl=pt-BR\&ct=clnk\&gl=br

CANDAU, Joël. Memória e Identidade. São Paulo: Contexto, 219 p. 2012.

CARDOZO, José Carlos da Silva. A tutela de crianças na Belle Époque Porto-Alegrense. História, Educação e Sociedade no RS. Autora: Guacira Lopes Louro. Cadernos Educação e Realidade $\mathrm{n}^{\circ}$ 1. UFRGS, 1986.

CARVAlHAL, Juliana Pinto. Maurice Halbwachs e a questão da memória. Revista Espaço Acadêmico, n. 56, jan de 2006.

HERRLEIN JR, Ronaldo. A peculiaridade da transição capitalista no Rio Grande do Sul, 18891930. $1^{\circ}$ Encontro de Economia Gaúcha, 2002. Disponível em <http://www.ww.fee.com.br/sitefee/download/eeg/1/mesa_12_herrleinjr.pdf> Acesso em 16 maio 2013.

KIEFER, Nidia Beatriz Nunes. Prelúdio: uma proposta de educação musical: 1982-2002. 2005. Disponível em < http://www.lume.ufrgs.br/handle/10183/6565> Acesso em 16 maio 2013.

MARTINS, José S. Sociologia da fotografia e da imagem. São Paulo: Editora Contexto, 2008, 207 páginas. Disponível em < http://www.scielo.br/scielo.php?pid=S010320702009000100014\&script=sci_arttext > Acesso em 29 jul 2013.

PESAVENTO, Sandra Jatahy. A construção de uma Porto Alegre imaginária - uma cidade entre a memória e a história. In GRIJÓ et al, Capítulos de história do Rio Grande do Sul, p179208. 2004.

PETERSEN, Sílvia Regina Ferraz; SCHMIDT, Benito Bisso. O movimento operário no Rio Grande do Sul: militantes, instituições e lutas (das origens a 1920). Capítulos da Historia do Rio Grande do Sul. Porto Alegre: Editora da UFRGS, 2004. 
POLLAK, Michael. Memória e identidade social. Rio de Janeiro: UFRJ, vol5, n.10, p.200-212, 1992.

QUINTANA, Gabriela R. Narrativas de la imagen: Memoria, relato y fotografía. 2009. Disponível em < http://www.antropologiavisual.cl/imagenes13/imprimir/raposo.pdf.> Acesso em 29 setembro 2013.

SANHUDO, Ary Veiga de. Porto Alegre: Crônicas da minha cidade, 1961 apud AXT\&SCLIAR, Parque Farroupilha "Redenção" Histórias de Porto Alegre, p 67-71. 2011.

SATURNINO, Edison L. Imagem, memória e educação. Um estudo sobre os modos de ver e lembrar, $2005 . \quad$ Disponível em <http://www.lume.ufrgs.br/bitstream/handle/10183/6679/000533140.pdf?sequence=1> Acesso em 30 de julho 2013.

VIZENTINI, Paulo Gilberto Fagundes. Do curso geral à escola técnica de comercio 19091979. Porto Alegre: UFRGS, 1979.

ZONABEND, Françoise. La Mémoire Longue: temps et histoires au village . Paris: PUF, Imagens: Acervo Institucional Acervo Pessoal - Prof. Paulo Schinini Museu UFRGS. 1980.

\section{Imagens}

Acervo Institucional

Acervo Pessoal - Prof ${ }^{\circ}$ Paulo Schenini

Museu UFRGS

\section{Entrevistas}

CORSO, Laura Vellinho - Professor aposentado do IFRS - Campus Porto Alegre.

FARIAS, Claudio Vinicius. - Professor do IFRS- Campus Porto Alegre.

HECK, Julio Xandro. Professor e Vice-Diretor atual do IFRS - Campus Porto Alegre.

KARWASTSKI, Walter - Professor do IFRS - Campus Porto Alegre

SANGOI, Paulo Roberto. Professor e Diretor atual do IFRS - Campus Porto Alegre.

SCHININI, Paulo. - Professor aposentado da Escola Técnica de Comercio - UFRGS.

SCHWANKE, Oswaldo Carlos - Corretor de Seguros, Ex-aluno da Escola Técnica.

VIEIRA, Lúcio Olímpio de Carvalho - Professor de Química - IFRS

\section{Arquivo documental}


ROSITO, Aldo Antonello. - Ex- Diretor e Professor aposentado do IFRS - Campus Porto Alegre.

RICHTER, Liana Yara. -Ex- Diretora e Professora aposentada do IFRS - Campus Porto Alegre.

Recebido em: 12/09/2013 Aprovado em: 10/10/2013 